\title{
A TECNOLOGIA ASSISTIVA EM BIBLIOTECAS PÚBLICAS: UMA ABORDAGEM PRELIMINAR SOBRE SUA IMPORTANCIA E CONTRIBUIÇÃO PARA USUÁRIOS COM DEFICIÊNCIA
}

\author{
Danielle Da Silva Pinheiro Wellichan \\ Mestra em Ciência da Informação - PPGE-UNESP, Marília \\ Doutoranda em Educação \\ dany_unesp@yahoo.com.br
}

\author{
Eduardo José Manzini \\ Livre-Docente do Departamento de Educação Especial \\ Programa de Pós-Graduação em Educação - PPGE - UNESP, Marília \\ ejmanzini@uol.com.br
}

\section{Resumo}

\begin{abstract}
As bibliotecas públicas estão em constante mudança e, por isso, enfrentam crises e desafios necessários para atender a sociedade. Com o advento da sociedade da informação, novas tecnologias adentraram o ambiente informacional trazendo oportunidades para as pessoas com deficiência e desafios para bibliotecários que precisam estar capacitados e sensibilizados de sua responsabilidade diante desse usuário especial. Surgem nesse contexto, como recursos e equipamentos, a tecnologia assistiva, para proporcionar melhores condições de vida para tais usuários e oportunizar a inclusão deles na busca pela informação e participação ativa, o mais independente possível no ambiente. Por meio da disponibilização da tecnologia assistiva as bibliotecas estão buscando ser significativas para a inclusão de pessoas com deficiência e para descrever como está sendo esse processo, buscou-se, por meio da literatura, subsídios para discutir sobre essa realidade. Verificou-se que embora a tecnologia esteja disponível nos ambientes, é preciso rever práticas, serviços e atuações para contribuir de fato para a inclusão e o uso mais significativo dos recursos e equipamentos da tecnologia assistiva nas bibliotecas.
\end{abstract}

Palavras-chave: Tecnologia Assistiva. Biblioteca Pública. Bibliotecário. Deficiência. Educação Especial.

\section{INTRODUÇÃO}

Desde o final do século XX (OMOTE, 2004), a discussão sobre as questões relacionadas às pessoas com deficiência conquistaram maior espaço na sociedade e com ela, novas demandas, adaptações e legislações foram elaboradas e estabelecidas com a intenção de oferecer melhores condições e qualidade de vida dentro de suas limitações ou especificidades.

No ambiente informacional, a chegada das novas tecnologias em comunicação e informação somou-se ao cenário citado alterando as rotinas das bibliotecas, exigindo atuações, produtos e serviços que atendam a todos de forma significativa e inclusiva. Nesse sentido, os recursos e equipamentos da tecnologia assistiva surgiram para apoiar não só as pessoas com necessidades especiais, mas também todos os profissionais que trabalham pela inclusão ou inserção de minorias na sociedade.

Diante dessa necessidade social, foi criado, na década de 90, o Manifesto sobre as Bibliotecas Públicas pela Federação Internacional das Associações de Bibliotecários (IFLA) e a UNESCO (Organização das Nações Unidas para a 
Educação, a Ciência e a Cultura) cujo objetivo foi formalizar que os serviços oferecidos por elas devem ser pautados na igualdade de acesso para todos, independentemente de idade, raça, gênero, religião, nacionalidade ou condição social, com o objetivo de disponibilizar serviços e materiais específicos para todo usuário, como, por exemplo, minorias linguísticas, pessoas com deficiência, hospitalizadas ou reclusas, para refletir a pluralidade e a diversidade da sociedade.

Segundo o manifesto, a missão das bibliotecas públicas está diretamente associada a informação, alfabetização, educação e cultura para criar e fortalecer hábitos desde a primeira infância; apoiar a educação individual e a autoformação em todos os níveis; assegurar meios para o desenvolvimento pessoal de forma criativa com estímulo à criatividade e promoção do conhecimento sobre a herança cultural, o apreço pelas artes e inovações cientificas. Além disso, também é missão da biblioteca pública possibilitar o acesso as formas de expressão cultural; fomentar o diálogo e a diversidade cultural; apoiar a tradição oral, disponibilizar serviços de informação adequados as necessidades da comunidade, participar e criar atividades de alfabetização para diferentes grupos etários (IFLA, 1994). Embora no manifesto a biblioteca pública seja o foco da questão, os objetivos e as missões também podem ser compartilhados com outros tipos de biblioteca, salvo especificidades que cada uma possua.

Nesse contexto, pessoas com deficiência devem ter acesso à informação e aos ambientes garantidos e facilitados de forma que se sintam naturalmente parte da sociedade. Porém, na realidade, a luta pelos direitos das pessoas com deficiência pela equidade é fato reconhecido e em constante busca, pois o sentimento de não pertencimento é reafirmado diante de situações e ambientes que reforcem suas limitações e/ou dificuldades de uso ou acesso. Surge aí a oportunidade de vincular tecnologias em favor da inclusão dialogando com a Educação Especial para relacioná-las ao cotidiano, conforme afirmou Manzini (2005, p.82)

Os recursos de tecnologia assistiva estão muito próximos do nosso dia-a-dia. Ora eles nos causam impacto devido à tecnologia que apresentam, ora passam quase despercebidos. Para exemplificar, podemos chamar de tecnologia assistiva uma bengala, utilizada por nossos avós para proporcionar conforto e segurança no momento de caminhar, bem como um aparelho de amplificação utilizado por uma pessoa com surdez moderada ou mesmo um veículo adaptado para uma pessoa com deficiência física.

Sob esta perspectiva, é preciso rever a existência dos recursos e equipamentos da TA e contextualizar as pessoas com deficiência para buscar reais melhorias quanto ao acesso e a utilização, mas principalmente, sobre o que está sendo feito deles no ambiente informacional.

\section{A BIBLIOTECA PÚBLICA COMO ESPAÇO DE PROMOÇÃO E DISSEMINAÇÃ̃O DA INFORMAÇÃO, EDUCAÇÃO, CULTURA E LAZER}

Almeida Jr. (1997, p.22) descreveu a biblioteca pública como "[...] reflexo e causa das transformações da sociedade; deve receber influências, interferir, ser início, meio e fim das alterações sociais, numa sequência interminável". É sob essa ótica que a biblioteca pública busca seu significado ao ser influenciada pelas novas demandas que a tecnologia e a sociedade lhe atribuem constantemente. Conforme Milanesi (2013, p.60) descreveu, no Brasil, as bibliotecas públicas

[...] estão entre dois tempos: o seu próprio modelo, que remete ao século XIX, e a necessidade de trazê-las para o século XXI. Enquanto o primeiro tempo deve ser superado, o segundo ainda deverá ser alcançado, como desafio técnico e políticosocial. Enquanto o primeiro oferece recursos conhecidos e acessíveis, o segundo depende de decisões que ultrapassam o campo técnico.

Ultrapassar esse campo citado conforme o autor mencionou, exige atender suas funções tradicionais (informativa, cultural, recreativa e educacional) e estar acessível para todo tipo de usuário para disponibilizar produtos e serviços que possibilitem sua participação no ambiente. No entanto, quando a acessibilidade é mencionada na biblioteca, seu significado precisa estar muito além, pois conforme Manzini (2014, p.20) “[...] as condições de acessibilidade devem estar fora 
da pessoa ou do usuário. Essas condições fazem parte dos espaços; mobiliários; equipamentos urbanos; edificações e dispositivos de comunicação e informação."

E nesse sentido, não são só as barreiras físicas que se relacionam a acessibilidade e que podem comprometer a vida, o desenvolvimento e a participação da pessoa com deficiência na sociedade, as atitudes sociais diante das pessoas com deficiência são grandes responsáveis por momentos de constrangimento e exclusão. No ambiente informacional (independentemente de sua tipologia), por exemplo, um bibliotecário que não consegue interagir com um usuário com deficiência intelectual, surdo ou com deficiência auditiva; um ambiente que não ofereça materiais ou tecnologias que permitam a permanência do cego ou deficiente visual; ou que apresente pontos de perigo ou dificuldade para um deficiente físico se locomover e agir com independência e autonomia na busca pela informação, são exemplos que podem acontecer e, por isso, devem ser considerados e trabalhados de forma constante e não apenas quando houver um caso em evidencia.

De modo geral, as capacitações profissionais acontecem mediante situações de emergência ou esporádicas e são oferecidas de forma temporal, o que condiciona as adaptações ou a aquisição de tecnologia a questão de verbas, projetos e financiamentos que nem sempre estão disponíveis, porém, conforme Omote (2004 apud PINHEIRO ${ }^{1}, 2004$, p. 74)

Deve-se pensar em função de todo e qualquer possível usuário e ao falar em acessibilidade e inclusão, a gente não pode nem pensar em contabilizar custo e benefício, ainda que um único usuário venha fazer uso de um determinado recurso, este deve estar presente. Do contrário, não há razão e não se justifica toda essa defesa que se faz apaixonadamente no sentido de igualdade de direito etc. Não importa se é um só usuário, ou se são 50, 200, 400 , desde que haja uma única pessoa, seu

\footnotetext{
1 OMOTE, S. Entrevista concedida para coleta de dados de trabalho de conclusão de curso. IN: PINHEIRO, D.S. O bibliotecário e o usuário especial em unidades de informação: formação e realidade profissional. 2004. 146f. Trabalho de Conclusão de Curso em Biblioteconomia. Faculdade de Filosofia e Ciências. Universidade Estadual Paulista, Marília, SP.
}

direito de ter acesso à informação tem que ser assegurado.

Para pensar em função dos usuários, conforme Omote citou, está entre os serviços técnicos do bibliotecário, os estudos de usuários que buscam conhecer e "[...] identificar a frequência de uso de determinado material nas unidades de informação, perfil, dificuldades de determinados grupos em bibliotecas ou serviços de informação" (WELLICHAN, 2015, p. 31). Atualmente, os estudos de comportamento informacional podem ser considerados como uma ampliação do estudo de usuário e embora visem compreender melhor o contexto da busca, processamento e transferência da informação (WILSON, 1999), podem atuar como uma complementação importante para contextualizar a realidade do usuário especial e auxiliar o bibliotecário diante das necessidades desse e de outros grupos no ambiente informacional.

Embora seja o estudo de usuário um dos temas mais abordados na literatura da área da Ciência da Informação, pouco abordam sobre a questão da deficiência de forma especifica (CONEGLIAN; CASARIN, 2014).

Em um levantamento realizado na Base de Dados em Ciência da Informação (BRAPCI) Silva, Santos e Rodrigues (2011) encontraram 77 trabalhos sobre estudo de usuários, sendo 36 de usuários com deficiência e apenas um sobre o usuário com surdez. Coneglian e Casarin (2014) em trabalho semelhante (utilizando como filtros os termos "deficiência" e depois o mesmo termo associado a "biblioteca") consultaram as bases de periódicos as CAPES, Pathernon (UNESP), SIBiUSP (USP), Scielo, Dedalus (USP) e Sistema de Bibliotecas da Universidade Estadual de Londrina (UEL) e levantaram no período de 2001 a 2012 artigos científicos nacionais sobre bibliotecas e deficientes e constataram que " [...] há pouco material indexado nas bases de dados pesquisadas e catálogos com os filtros apontados [..] quando pertinentes à temática, há uma predominância de pesquisas voltadas para a deficiência visual (CONEGLIAN; CASARIN, 2014, p. 222).

$\mathrm{O}$ fato é que, mesmo após movimentos mundiais importantes sobre a inclusão de pessoas com deficiência (Declaração de Salamanca, por exemplo em 
1994) a existência de normas (NBR 9050), leis e decretos (como o n.3.298 que dispõe sobre a Política Nacional para a Integração da Pessoa Portadora de Deficiência) pouco ainda é criado na sociedade e muito se torna adaptado, como rampas, banheiros, transportes e instituições públicas, mas o estigma social do indivíduo persiste, pois, a atitude de incluir em si é pouco considerada, já que, de forma geral, há mais inserções do que inclusões na sociedade.

Assim, a partir da chegada dos recursos e equipamentos de TA nas bibliotecas, uma nova oportunidade de inclusão surge, desde que bem aproveitada.

\subsection{A TECNOLOGIA ASSISTIVA}

Considerada como uma alternativa que visa suprir alguma incapacidade relacionada entre a capacidade funcional da pessoa e a demanda por determinada atividade, os recursos e equipamentos da TA buscam proporcionar melhor qualidade de vida, ao oferecer uma oportunidade de compensação da deficiência que permite ao indivíduo a execução de tarefas e a participação de atividades diversas de seu interesse (BRACCIALLI, 2007)

Assim, considerar a independência, inclusão, ampliação da comunicação, mobilidade e habilidades de seu aprendizado são objetivos da TA se diferem em produtos e serviços quando se considera recurso como todo ou qualquer item, equipamento, produtos ou sistema utilizado para manter ou melhorar a funcionalidade de pessoas com deficiência; e serviço as ações realizadas às pessoas com deficiência para escolher ou selecionar os recursos (AMORIM, 2013)

Segundo o Comitê de Ajudas Técnicas (CAT) a TA pode ser entendida como

[...] área do conhecimento, de característica interdisciplinar, que engloba produtos, recursos, metodologias, estratégias, práticas e serviços que objetivam promover a funcionalidade, relacionada à atividade e participação, de pessoas com deficiência, incapacidades ou mobilidade reduzida, visando sua autonomia, independência, qualidade de vida e inclusão social (BRASIL, 2007).

A TA visa apoiar e desenvolver produtos e oferecer serviços para promover a vida independente e a inclusão de pessoas com deficiência ou necessidades especiais (SARTORETTO; BERSCH, 2017). Mas, se a tecnologia assistiva possibilita a inclusão por meio de áreas como a de "[...] comunicação suplementar e alternativa, de adaptações para acesso ao computador, atividades e equipamentos para auxiliar déficits sensoriais e de postura" conforme Deliberato (2005) citou, por que sua presença nas bibliotecas não tem sido suficiente para que usuários especiais utilizem o ambiente informacional também?

Com recursos diversificados, é cada vez mais comum encontrar tais tecnologias no ambiente informacional, porém, para que a inclusão de pessoas com deficiência de fato aconteça nesse ambiente, é preciso que o bibliotecário esteja capacitado para utilizá-la e que serviços especializados sejam elaborados e disponibilizados para tais usuários. A prática bibliotecária tem sido favorecida pela área da TA e desafiada também, pois evidencia que apenas a presença delas não garante a inclusão. São os serviços e materiais especializados que atraem e podem proporcionar ao usuário especial $^{2}$ o sentimento de pertencimento ao ambiente.

\section{OS RECURSOS DE TECNOLOGIA ASSISTIVA EM BIBLIOTECAS}

Por meio de editais públicos, financiamentos institucionais, aquisições ou doações empresariais, as bibliotecas têm recebido recursos de TA para serem disponibilizados nas bibliotecas, como ampliador automático, scanner leitor de mesa, teclado ampliado, mouse estacionário, leitor de tela NVDA, computador, linha $\mathrm{e}$ impressora Braille nas bibliotecas, mas será que a presença desses recursos está garantindo que as pessoas com deficiência usufruam do ambiente informacional em sua totalidade? A inclusão ou a inserção no ambiente informacional está acontecendo como esperávamos?

Embora tais recursos estejam disponíveis e acervos especiais tenham sido criados, tratados e disponibilizados, não há ainda uma estatistica que demonstre o crescimento no

\footnotetext{
2 Atribuiu-se o termo de usuário especial neste artigo para todo indivíduo que possuir deficiência permanente ou adquirida, independente de qual seja.
} 
uso e na frequencia do usuário com deficiência em bibliotecas.

Em alguns casos, a falta de apoio familiar em levar ou acompanhá-los até à biblioteca ou simplesmente a falta de hábito em frequentar o local, são possíveis razões para essa questão da procura, mas se aplica para todas as deficências?

É fato que a tecnologia em dispositivos móveis também proporciona o acesso mais rápido à informação sem que exija para isso deslocamento físico da pessoa com deficiência. Porém, uma outra variável precisa ser considerada diante dessa questão em especifico: a falta de serviços especializados ou direcionados para esse público em especial, afinal, se há materiais especializados e equipamentos de tecnologia assistiva disponíveis, porque o usuário ainda não faz uso do ambiente e seus recursos?

Como citado anteriormente, o bibliotecário precisa estar capacitado para os recursos e equipamentos da TA e conforme é possível verificar, existem esses momentos de capacitação tanto para os recursos quanto para saber um pouco mais sobre as pessoas com deficiência. Então a hipótese que se estabelece é que os serviços para esse público ainda não estejam sendo oferecidos ou precisam ser melhor trabalhados para atrair esse usuário.

Embora comumente confundidos e relacionados, o termo acesso se refere ao processo de atingir algo, enquanto acessibilidade reflete algo mais concreto, conforme Manzini (2012) descreveu. Assim não é possível confundir acesso e acessibilidade pois possuem diferentes significados.

Nas bibliotecas públicas (em especifico) cujo público é variado em função de seus objetivos e funções, tratar a questão do acesso pode ser relativamente mais fácil do que a da acessibilidade, uma vez que a segunda está diretamente ligada aos serviços oferecidos na instituição, muitas vezes independente dos recursos oferecidos à população, além de atitudes sociais.

A acessibilidade informacional para os usuários especiais não pode estar apenas ligada a TA, embora precise dela para oferecer maiores condições para o acesso à informação. Questões de infraestrutura, espaço físico, equipamentos e mobiliário adaptado, materiais diversificados para o acervo institucional, sinalização especial, softwares que possibilitem a leitura para pessoas com deficiência visual, ou a conversão de texto na Língua Brasileira dos Sinais (Libras) precisam estar presentes nos ambientes informacionais que busquem proporcionar um ambiente inclusivo, no entanto, é na atitude social e pessoal de cada profissional e na variedade de serviços oferecidos a esse usuário especial que a inclusão de fato pode acontecer.

A exemplo disso, Miguel (2015) apresentou, em sua dissertação, um projeto de intervenção realizado em uma biblioteca pública em Lisboa, onde trabalhou com o uso de Histórias Multissensoriais (HMS), cuja abordagem pedagógica foi criada pensando em crianças e jovens com deficiências múltiplas ou com diagnósticos associados ao Transtorno do Espectro Autista (TEA).

Segundo a autora, as HMS são opções viáveis para aquelas pessoas que não usam a fala para se comunicar, nem entendem a palavra escrita, pois foge um pouco ao formato do livro tradicional (impresso), são confeccionadas em material diferenciado e que explora o lado sensorial, apresentando em sua estrutura histórias, figuras, conteúdos curriculares em diferentes tipos de materiais.

A biblioteca estudada fica localizada no centro de Portugal, e segundo a autora possui boa acessibilidade arquitetônica e organizacional, está informatizada, tem amplo espaço interno e possui parcerias com escolas municipais e instituições para auxílios em financiamentos e projetos. Por meio de um projeto de intervenção, a autora realizou um programa semanal das sessões de conto para dinamizar as HMS no ambiente da biblioteca e com isso atrair crianças e jovens com deficiência que não utilizavam a biblioteca. Utilizando do contato direto e da divulgação em locais estratégicos, as sessões envolveram pais, filhos e equipe de trabalho local, apresentando resultados positivos e que indicaram interesse pela continuidade do trabalho desenvolvido, conforme a bibliotecária local comentou durante entrevista à autora responsável pelo projeto (MIGUEL, 2015, p. 96)

\footnotetext{
[...] “Eu gostei bastante de assistir...” [...] "... penso que foi uma mais-valia, muito positiva nessa perspectiva..." “... gostaram [a equipe da biblioteca] de ver a atividade $e$
} 
admiraram..." A própria manifestou o desejo de repetir a experiência no futuro dizendo " ...gostaria muito que viéssemos a concretizar alguma atividade nesta área, para este público..."

“... ver que eles reagiam e a expressão no rosto deles dava perfeitamente para ver que eles estavam a gostar, a interagir com quem comunicava com eles..." “... deu oportunidade aos sábados, viessem aqui $e$ pudessem usufruir do conto e do espaço..."

Quanto a HMS: “... é totalmente diferente..." “... não fazia ideia que era assim que trabalhavam com estes meninos..." Até porque nas bibliotecas públicas faz parte dos objetivos terem programação para quaisquer pessoas..." “... falta-nos as bases científicas...” “... o problema maior é a comunicação, depois ter formação para..." “...acho que devíamos ter sempre uma parceria convosco porque são as pessoas que têm formação específica...” “... são materiais que até nós próprias, não é, com a ajuda de professoras desta área (...) poder-nosiam ajudar a ter também aqui..."

No trabalho de Miguel (2015) fica clara a necessidade de oferecer estrutura, recursos (acervo e tecnologia), mas também buscar usuários potenciais. É preciso que a parceria citada pela bibliotecária no trecho acima, seja frequente porque é necessária, afinal, a complementação das áreas na prática resultam não só na troca de experiências, como no próprio desenvolvimento humano $\mathrm{e}$ profissional de cada indivíduo dentro de seu mercado de trabalho.

\section{CONSIDERAÇÕES FINAIS}

Os recursos e equipamentos da TA contribuem de forma significativa para a qualidade de vida das pessoas com deficiência e amplia as possibilidades de inclusão na sociedade, mas apenas dispor da tecnologia não é suficiente. Como já citado ao longo do texto, há uma diferenciação na TA entre os termos (recurso, equipamento e serviço) que precisa ser compreendida para ser colocada em prática e diante deles propor melhorias e maior utilização da tecnologia.

Comumente, as bibliotecas possuem recursos tecnológicos que não são utilizados conforme seus objetivos, pois a questão de acesso não é só o maior dos problemas em alguns casos. Questões de incentivo familiar e hábitos culturais são problemáticas que a sociedade carrega ao longo dos anos e afeta a vida das pessoas em geral diante de instituições como as bibliotecas. Se for com pessoas com deficiência então, a situação se torna mais delicada, pois há mais fatores associados como educação, transporte, recursos e disponibilidade.

Projetos governamentais e financiamentos são importantes para o desenvolvimento de uma nação e precisam ser motivos de investimentos mais constantes, assim como a capacitação de pessoas para atender as novas demandas sociais. Mas associado aos investimentos e capacitações as atenções precisam também estar voltadas a formação continuada de profissionais para saberem atuar diante dessas novas demandas. Mais do que tecnologia, serviços precisam ser criados em função dos grupos especiais e, para isso, a colaboração de outras áreas da ciência favorece a todos.

Não basta possuir recursos e equipamentos da TA, é preciso estabelecer parcerias e diversificação em seus serviços para buscar mais usuários especiais, porém, será preciso um árduo trabalho de divulgação e principalmente de conscientização para que famílias e instituições aproveitem o espaço e os recursos oferecidos de forma significativa. Neste sentido, reafirma-se que a importância da parceria entre profissionais é uma necessidade não só diante da dela, mas na própria criação e desenvolvimento de atividades e serviços especializados. Além disso, a necessidade da comunicação cientifica se torna evidente para divulgar o que é realizado no cotidiano das bibliotecas e compartilhar experiências que podem servir de inspiração e discussão para a área da Ciência da Informação e para a atuação de seus profissionais. 
Public libraries are constantly changing and, therefore, face crises and challenges that are necessary to serve society. With the advent of the information society, new technologies have penetrated the informational environment bringing opportunities for people with disabilities and challenges for librarians who need to be empowered and sensitized of their responsibility to this special user. In this context, as resources and equipment, the assistive technology to provide better living conditions for these users and to include them in the search for information and active and as independent participation in the environment as possible. Through the provision of assistive technology, libraries are seeking to be meaningful for the inclusion of people with disabilities and to describe how this process is being studied, through the literature, we sought subsidies to discuss this reality. It has been found that while technology is available in the environments, it is necessary to review practices, services and actions to effectively contribute to the inclusion and more significant use of assistive technology resources and equipment in libraries.

Keywords: Assistive technology; Public library; Librarian; Deficiency. Special education.

\section{REFERÊNCIAS}

\author{
ALMEIDA Jr., O.F. Bibliotecas públicas e \\ bibliotecas alternativas. Londrina: UEL, \\ 1997.
}

AMORIM, G.C. et al. Tecnologia assistiva na estrutura e organização do AEE na Educação Infantil: conhecimento e uso na perspectiva do gestor. In: ENCONTRO DA

ASSOCIAÇÃO BRASILEIRA DE PESQUISADORES EM EDUCAÇÃO ESPECIAL, 3, 2013, Londrina. Anais... Londrina, p. 1661-1671. Disponível em:< http://www.uel.br/eventos/congressomultidisc iplinar/pages/arquivos/anais/2013/AT042013/AT04-010.pdf> Acesso em: 10 maio 2018.

BRACCIALLI, L.M.P. Tecnologia assistiva: perspectiva de qualidade de vida para pessoa com deficiência. In: VILARTA, R. et al. (Org.). Qualidade de vida e novas tecnologias. Campinas: Ipes Editorial, 2007. p. 105-114.

BRASIL. Secretaria dos Direitos Humanos. Comitê de Ajudas Técnicas. 2007. Ata da III reunião do Comitê de Ajudas Técnicas CAT. Disponível em: <
http://www.acessobrasil.org.br/CMS08/seopublicacoes-6.htm >. Acesso em: 10 maio 2018

CONEGLIAN, A.L.O.; CASARIN, H.C.S. Deficientes como usuários de informação. IN: CASARIN, H.C.S. (Org.) Estudos de usuário da informação. Brasília: Thesaurus, 2014. p. 220-254.

DELIBERATO, D. Seleção, adequação e implementação de recursos alternativos e/ou suplementares de comunicação. In: PINHO, S. Z.; SAGLIETTI, J. R. C. (Org.). Núcleo de ensino. São Paulo: EDITORA UNESP, 2005, v. 1, p. 505-519. Disponível em: < http://www.unesp.br/prograd/PDFNE2003/Se lecao, \%20adequacao.pdf $>$. Acesso em: 10 maio 2018

FEDERAÇÃO INTERNACIONAL DE ASSOCIAÇÕES DE BIBLIOTECÁRIOS E INSTITUIÇÕES. Manifesto da IFLA e UNESCO sobre bibliotecas públicas. 1994. Disponível em: < https://www.ifla.org/files/assets/publiclibraries/publications/PL-manifesto/plmanifesto-pt.pdf >Acesso em: 10 maio 2018. 
MANZINI, E.J. Considerações teóricas sobre acessibilidade: da definição às concepções atuais. In: MANZINI, E.J.; CORREA, P.M. Avaliação de acessibilidade na educação infantil e no ensino superio $r$. São Carlos: Marquezine \& Manzini: ABPEE, 2014. P.1727.

MANZINI, E.J. Acessibilidade em eventos científicos: contribuições da educação especial. Revista da Sobama, Marília, v. 13, n. 2, p. 37-42, Jul./Dez., 2012. Disponível em:<

http://www2.marilia.unesp.br/revistas/index.p hp/sobama/article/view/3908/2921> Acesso em: 20 maio de 2018.

MANZINI, E. J. Tecnologia assistiva para educação: recursos pedagógicos adaptados. In: Ensaios pedagógicos: construindo escolas inclusivas. Brasília: SEESP/MEC, 2005. p.82-86.

MANZINI, E. J. Considerações sobre a elaboração de roteiro para entrevista semiestruturada. In: MARQUEZINE, M. C.; ALMEIDA, M. A.; OMOTE; S. (Org.). Colóquios sobre pesquisa em Educação Especial. Londrina: Eduel, 2003. p.11-25.

MIGUEL, T.P.J.P. O uso de histórias multissensoriais numa biblioteca pública. 2015. 189f. Dissertação (Mestrado) - Escola Superior de Educação de Lisboa. Lisboa, Instituto Politécnico de, Lisboa. 2015.

Disponível em:<

https://repositorio.ipl.pt/handle/10400.21/466 9> Acesso em: 05 maio 2018.

MILANESI, L. Biblioteca pública: do século XIX para o XXI. Revista USP, São Paulo, n.97, p. 59-70, mar.2013. Dossiê Computação em nuvem. Disponível em:<

http://www.revistas.usp.br/revusp/article/view /61685/64574 > Acesso em: 15 maio 2018.

OMOTE, S. Inclusão: intenção e realidade. Marília: Fundepe, 2004.

PINHEIRO, D. S. O bibliotecário e o atendimento aos usuários com necessidades especiais em unidades de informação. Revista de Iniciação Científica da FFC, Marília, v. 4, n. 3, p.1-7, 2004. Disponível em: < http://www2.marilia.unesp.br/revistas/index.p hp/ric/article/view/95/96 >. Acesso em: 24 maio 2018.

SARTORETTO, M.L.; BERSCH, R. Assistiva tecnologia e educação. 2017. Disponível em:

http://www.assistiva.com.br/tassistiva.html> Acesso em: 20 abr. 2018.

\section{WELLICHAN, D.S.P. Comportamento} informacional de profissionais no domínio da saúde: um estudo junto ao Hospital de Reabilitação de Anomalias Craniofaciais da Universidade de São Paulo. 2015.128f. Dissertação (Mestrado em Ciência da Informação) - Universidade Estadual Paulista - UNESP, Marília, SP. Disponível em:< $<$ https://www.marilia.unesp.br/Home/PosGraduacao/CienciadaInformacao/Dissertacoes /wellichan ddsp me mar.pdf $>$ Acesso em 20 maio 2018.

WILSON, T. D. Models in information behaviour research. Journal of

Documentation, London, v. 55, n. 3, p. 249270, 1999. Disponível em: < http://informationr.net/tdw/publ/papers/1999J

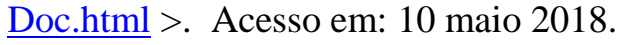

